\title{
ラットのストレス胃潰瘍発生および色素漏出に およぼす数種薬物の影響
}

\author{
中 根 貞 雄, 酒 井 健 \\ 大正製薬研究部* \\ (昭和48年 6 月 4 日)
}

\begin{abstract}
要約 : 本研究に执いて, 自律神経薬ほか諸種薬物の潰瘍形成と胃液分泌扰よび PSB 漏出量に およぼす影響を検討し，以下の結果を得た。1）本実験で，phenoxybenzamine を除き，スト レス潰瘍抑制作用を示した薬物は，潰瘍抑制量で胃液分泌減少と $\mathrm{pH}$ 上昇作用を示した。この ことは，ストレス潰瘍抑制には胃液分泌の抑制が重要な要因であることを示唆するものと考兄 られる。. 2) atropine は, 潰瘍抑制量に扎いて, ストレスによるPSB 量減少に対し, 少くと も增強作用を示さなかった。 また, propranolol, DCI および chlorpromazine は, ストレス による PSB 量減少に対し，むしろ阻止的であった。これより，ストレスによる胃粘膜血流の 阻止ないし抑制が抗潰瘍作用の一因となると考えられる.
\end{abstract}

緒 言

さきに私たちは1,2)，ラットにおいてストレス負荷が胃液中への Pontamine Sky Blue 6BX (以下 PSB と 略す) 漏出を著しく減少すること、および reserpine その他数種薬物のストレス潰瘍生成におよぼす影響と PSB 漏出量との間に密接な関係があることを報告した。

本報では, 自律神経作用薬ほか諸種薬物のストレス潰瘍形成, 胃液分泌および PSB 漏出量におよぼす影響 を検討した。

\section{実験方法および材料}

\section{1．ストレス負荷による胃潰礉誘発}

ドンリュウ系雄ラット（体重約 $250 \mathrm{~g}$ ) を使用し, Takagi and Okabe の方法3)に従い，拘束ヶージに入 れ, 水温 $23^{\circ} \mathrm{C}$ の水槽中に胸骨下縁まで浸し，7時間放置した，その後，頭部を叨打致死させ胃を摘出した．噴

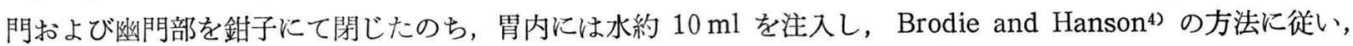
約 5 分, $0.5 \%$ formalin 液中に置いたのち, 大弯側に沿って切開した. 肉眼的観察により, 粘膜面の潰瘍性変 化を示す部分の数および面積を測定し, その総和を潰瘍係数とした.

\section{2. 胃液への色素漏出試験}

ドンリュウ系雄ラット（体重約 $250 \mathrm{~g} ）$ を用い, Takagi and Kawashima の方法5) 飞従い, 一昼夜絶食後, 軽度の ether 麻酔下に開腹し, 幽門部を結紮した。 経口的に胃チューブを導入し, 加温生理食塩水にて胃内容 を洗浄後腹壁を縫合閉鎖した。つぎに，加温生理食塩水を $2 \mathrm{ml} / 100 \mathrm{~g}$ 胃内に注入後，直ちに，尾静脈より $5 \%$ $\mathrm{PSB}$ を $0.2 \mathrm{ml} / 100 \mathrm{~g}$ 投与し, 上述のように水温 $23^{\circ} \mathrm{C}$ にて拘束水浸ストレスを負荷した. 3 時間後, ラットを 撲殺し, 胃液を採取した。胃液分泌量は, 採取量より胃内に注入した生理食塩水量を差引いた值とした。胃液中 のPSB 量測定は, Takagi and Kawashima の方法5) と従った。なお, PSB 量は, $\mu \mathrm{g} / 100 \mathrm{~g}$ 体重で表わした.

検した薬物は, atropine sulfate (東京化成), scopolamine hydrochloride (山之内), tetraethylammonium chloride (以下 TEA と略す) (東京化成), dibenamine hydrochloride (東京化成), phenoxybenzamine (以下 PBZ と略す) (東京化成), propranolol (住友化学), dichloroisoproterenol (以下 DCI と略寸) (Ald-

* 正171 東京都豊島区高田3-34-1 
rich), papaverine (大正), vasopressin (三共), chlorpromazine (シオノギ), pentobarbital (大正) であ りストレス負荷30分前に腹腔内に投与した．毎実験に薬物非投与群を対照とした。

\section{実 験 成 績}

\section{1. 自律神経作用薬その他のストレス潰場形成におよほすす影響}

Table 1 に示すように, 副交感神経遮断薬 Atropine, scopolamine 各 $5 \mathrm{mg} / \mathrm{kg}$ (i.p.) は, ストレス潰瘍 の形成を有意に抑制した。節遮断薬 hexamethonium は, $10,20 \mathrm{mg} / \mathrm{kg}$ で潰湟形成を有意に抑制したが, TEA $40 \mathrm{mg} / \mathrm{kg}$ の抑制作用は軽度にすぎなかった. Adrenaline 性 $\alpha$ 遮断薬 dibenamine $50 \mathrm{mg} / \mathrm{kg}$ の抑制も軽度に すぎなかったが, PBZ $10 \mathrm{mg} / \mathrm{kg}$ は有意の抑制を示した。 また， $\beta$ 遮断薬 propranolol $20 \mathrm{mg} / \mathrm{kg}$ および DCI $40 \mathrm{mg} / \mathrm{kg}$ はいずれも有意に潰瘍形成を抑制した.

平滑筋作用薬 papaverine $50 \mathrm{mg} / \mathrm{kg}$ および vasopressin $10 \mathrm{u} / \mathrm{kg}$ は, 潰瘍形成に対し, 軽度抑制的にす ぎなかった。

中枢抑制薬 chlorpromazine $5 \mathrm{mg} / \mathrm{kg}$ は, 潰愓形成を完全に抑制したが, pentobarbital-Na $20 \mathrm{mg} / \mathrm{kg}$ は 潰瘍形成を抑制しなかった。

Table 1. Effect of drugs on stress ulcer in rats.

\begin{tabular}{lccccc}
\hline \multirow{2}{*}{ Drug } & \multirow{2}{*}{$\begin{array}{c}\text { Dose } \\
(\mathrm{mg} / \mathrm{kg})\end{array}$} & \multicolumn{2}{c}{ No. of rats } & & \\
\cline { 3 - 4 } & & Control & Test & & \\
Atropine & 5 & 8 & 8 & 93.4 & $<0.01$ \\
Scopolamine & 5 & 8 & 8 & 97.8 & $<0.01$ \\
Hexamethonium & 10 & 8 & 8 & 85.8 & $<0.01$ \\
& 20 & 12 & 12 & 91.2 & $<0.01$ \\
TEA & 40 & 8 & 8 & 29.7 & $>0.05$ \\
Dibenamine & 50 & 8 & 8 & 35.6 & $>0.05$ \\
PBZ & 10 & 8 & 8 & 65.7 & $<0.01$ \\
Propranolol & 20 & 8 & 8 & 61.8 & $<0.05$ \\
DCI & 40 & 8 & 8 & 97.5 & $<0.01$ \\
Papaverine & 50 & 6 & 6 & 12.3 & $>0.05$ \\
Vasopressin & $10 \mathrm{u} / \mathrm{kg}$ & 10 & 10 & 42.1 & $>0.05$ \\
Chlorpromazine & 5 & 8 & 8 & 100.0 & $<0.01$ \\
Pent & 20 & 8 & 8 & 4.4 & $>0.05$ \\
\hline
\end{tabular}

*: Level of significance was calculated according to student's $t$-test.

TEA : Tetraethylammonium chloride. PBZ: Phenoxybenzamine.

DCI : Dichloroisoproterenol. Pent: Pentobalbital-Na.

\section{2. 自律神経作用薬の胃液分泌および PSB 量におよぼす影響}

a. 副交感神経遮断薬

ストレス非負荷ラットでは, atropine $5 \mathrm{mg} / \mathrm{kg}$ は胃液分泌阻止, $\mathrm{pH}$ 上昇および PSB 量軽度減少をきた した. scopolamine $5 \mathrm{mg} / \mathrm{kg}$ もまた同様の影響をおよぼしたが, PSB 量減少は有意でなかった (Table 2).

ストレス負荷ラットでは, 非負荷対照ラットに比し, 胃液分泌の減少, $\mathrm{pH}$ の軽微な上昇とともに, PSB 量 は減少すること, 前報1) のとおりである.これに対し, atropine $5 \mathrm{mg} / \mathrm{kg}$ 投与は, 胃液分泌を完全阻止し, $\mathrm{pH}$ を上昇したが, PSB 量にはストレス負荷に伴 5 以上の変化を与えなかった。一方, scopolamine $5 \mathrm{mg} / \mathrm{kg}$ は, 胃液分泌を阻止し， pH を上昇するとともに，さらに PSB 量を有意に減少した (Table 2).

b . 神経節遮断薬

ストレス非負荷時, hexamethonium $10 \mathrm{mg} / \mathrm{kg}$ は, 胃液分泌を減少し, $\mathrm{pH}$ を上昇するとともに, PSB 量 をやや減少した。 $20 \mathrm{mg} / \mathrm{kg}$ は, さらに影響が大で, PSB 量は有意に減少した. TEA $40 \mathrm{mg} / \mathrm{kg}$ は, 胃液分 
Table 2. Effect of parasympathetic blocking agents on gastric secretion and output of PSB in stressed and non-stressed rats.

\begin{tabular}{lcccccc}
\hline Treatment & $\begin{array}{c}\text { Dose } \\
(\mathrm{mg} / \mathrm{kg})\end{array}$ & $\begin{array}{c}\text { No. of } \\
\text { rats }\end{array}$ & $\begin{array}{c}\text { Volume } \\
\mathrm{ml}\end{array}$ & $\mathrm{pH}$ & \multicolumn{2}{c}{ PSB output } \\
\cline { 6 - 7 } & & & & & $\mu \mathrm{g} / 100 \mathrm{~g}$ & \% change \\
\hline $\begin{array}{l}\text { Non-stressed } \\
\text { Control }\end{array}$ & & 14 & $3.5 \pm 0.5$ & $1.3 \pm 0.1$ & $20.8 \pm 4.0$ & \\
$\quad \begin{array}{l}\text { Atropine } \\
\text { Control }\end{array}$ & 5 & 16 & $0^{* *}$ & $5.1 \pm 0.4^{* *}$ & $12.9 \pm 2.6$ & -38.1 \\
$\quad$ Scopolamine & 5 & 8 & $4.9 \pm 0.8$ & $1.1 \pm 0.1$ & $17.9 \pm 2.5$ & \\
Stressed & & & $0^{* *}$ & $3.6 \pm 0.4^{* *}$ & $16.8 \pm 5.6$ & -6.1 \\
$\quad$ Control & & 20 & $0.7 \pm 0.2$ & $1.7 \pm 0.2$ & $11.5 \pm 2.1$ & \\
Atropine & 5 & 19 & $0^{* *}$ & $3.5 \pm 0.4^{* *}$ & $11.1 \pm 2.6$ & -3.5 \\
$\quad$ Control & & 12 & $0.8 \pm 0.3$ & $1.5 \pm 0.1$ & $14.0 \pm 2.1$ & \\
$\quad$ Scopolamine & 5 & 11 & $0^{* *}$ & $2.3 \pm 0.2^{* *}$ & $6.8 \pm 1.7 *$ & -50.8 \\
\hline
\end{tabular}

Values are means \pm standard error. ${ }^{* *}: \mathrm{p}<0.01 ; *: \mathrm{p}<0.05$ when compared to control.

泌, PSB 量を減少したが, $\mathrm{pH}$ 上昇は明らかでなかった (Table 3).

ストレス負荷時, hexamethonium $10,20 \mathrm{mg} / \mathrm{kg}$ および TEA $40 \mathrm{mg} / \mathrm{kg}$ は, いずれも，胃液分泌を阻止 し， pH を上昇するとともに，ストレス負荷に伴う PSB 量減少を増強した (Table 3).

Table 3. Effect of ganglionic blocking agents on gastric secretion and output of PSB in stressed and non-stressed rats.

\begin{tabular}{|c|c|c|c|c|c|c|}
\hline \multirow{2}{*}{ Treatment } & \multirow{2}{*}{$\begin{array}{c}\text { Dose } \\
(\mathrm{mg} / \mathrm{kg})\end{array}$} & \multirow{2}{*}{$\begin{array}{l}\text { No. of } \\
\text { rats }\end{array}$} & \multirow{2}{*}{$\begin{array}{c}\text { Volume } \\
\mathrm{ml}\end{array}$} & \multirow{2}{*}{$\mathrm{pH}$} & \multicolumn{2}{|c|}{ PSB output } \\
\hline & & & & & $\mu \mathrm{g} / 100 \mathrm{~g}$ & $\%$ change \\
\hline \multicolumn{7}{|l|}{ Non-stressed } \\
\hline Control & & 8 & $4.3 \pm 0.5$ & $1.4 \pm 0.1$ & $22.3 \pm 5.8$ & \\
\hline Hexamethonium & 10 & 8 & $0.8 \pm 0.6^{* *}$ & $2.4 \pm 0.6^{*}$ & $18.0 \pm 3.2$ & -19.3 \\
\hline Control & & 8 & $5.0 \pm 0.3$ & $1.2 \pm 0.1$ & $25.1 \pm 6.2$ & \\
\hline Hexamethonium & 20 & 8 & $0 * *$ & $3.3 \pm 0.1^{* *}$ & $12.5 \pm 2.8^{*}$ & -50.2 \\
\hline Control & & 8 & $4.6 \pm 0.5$ & $1.2 \pm 0.1$ & $32.5 \pm 9.8$ & \\
\hline TEA & 40 & 8 & $1.7 \pm 0.8^{* *}$ & $1.4 \pm 0.1$ & $19.6 \pm 5.4$ & -39.7 \\
\hline \multicolumn{7}{|l|}{ Stressed } \\
\hline Control & & 8 & $0.9 \pm 0.2$ & $1.6 \pm 0.1$ & $12.0 \pm 3.5$ & \\
\hline Hexamethonium & 10 & 8 & $0 * *$ & $2.6 \pm 0.2^{* *}$ & $7.3 \pm 2.5$ & -39.2 \\
\hline Control & & 8 & $0.8 \pm 0.4$ & $1.6 \pm 0.2$ & $16.4 \pm 2.7$ & \\
\hline Hexamethonium & 20 & 8 & $0^{* *}$ & $3.1 \pm 0.2^{* *}$ & $8.6 \pm 2.7 * *$ & -47.5 \\
\hline Control & & 8 & $0.6 \pm 0.4$ & $1.4 \pm 0.1$ & $10.0 \pm 3.2$ & \\
\hline TEA & 40 & 8 & $0 * *$ & $2.8 \pm 0.1^{* *}$ & $7.1 \pm 1.8$ & -32.4 \\
\hline
\end{tabular}

Values are means \pm standard error. $* *: \mathrm{p}<0.01 ; *: \mathrm{p}<0.05$ when compared to control.

TEA : Tetraethylammonium chloride.

c. Adrenaline 性 $\alpha$ 遮断薬

ストレス非負荷時, dibenamine $50 \mathrm{mg} / \mathrm{kg}$ は, 胃液分泌減少, $\mathrm{pH}$ 上昇とともに PSB 量を有意に減少し

た. PBZ $10 \mathrm{mg} / \mathrm{kg}$ は, 胃液分泌, $\mathrm{pH}$ に有意の影響を示さなかったが, PSB 量を明らかに減少した.

ストレス負荷時, dibenamine $50 \mathrm{mg} / \mathrm{kg}$ は, 胃液分泌減少, $\mathrm{pH}$ 上昇をきたしたが, PSB 量はストレス負 荷による減少以上には減少しなかった。 PBZ $10 \mathrm{mg} / \mathrm{kg}$ は, 胃液分泌, $\mathrm{pH}$ に著明な影響を与えず, PSB 量の 減少もストレス負荷のみによる減少を軽度に越えるのみであった（Table 4). 
Table 4. Effect of $\alpha$-adrenergic blocking agents on gastric secretion and output of PSB in stressed and non-stressed rats.

\begin{tabular}{lcccccc}
\hline Treatment & $\begin{array}{c}\text { Dose } \\
(\mathrm{mg} / \mathrm{kg})\end{array}$ & $\begin{array}{c}\text { No. of } \\
\text { rats }\end{array}$ & $\begin{array}{c}\text { Volume } \\
\mathrm{ml}\end{array}$ & $\mathrm{pH}$ & \multicolumn{2}{c}{ PSB output } \\
\cline { 6 - 7 } & & & & & & \\
\hline Non-stressed & & & & & & \\
$\quad$ Control & & 9 & $3.6 \pm 0.9$ & $1.4 \pm 0.2$ & $21.8 \pm 6.4$ & \\
$\quad$ Dibenamine & 50 & 10 & $1.1 \pm 0.4^{* *}$ & $2.1 \pm 0.5$ & $12.8 \pm 2.1^{* *}$ & -41.3 \\
$\quad$ PBZ & 10 & 8 & $2.7 \pm 0.6$ & $1.3 \pm 0.1$ & $10.1 \pm 1.5^{* *}$ & -53.7 \\
Stressed & & & & & & \\
$\quad$ Control & & 12 & $0.7 \pm 0.3$ & $1.5 \pm 0.1$ & $8.4 \pm 2.0$ & \\
$\quad$ Dibenamine & 50 & 11 & $0.3 \pm 0.2$ & $2.1 \pm 0.5$ & $8.6 \pm 1.6$ & 2.4 \\
$\quad$ PBZ & 10 & 12 & $0.7 \pm 0.1$ & $1.7 \pm 0.1$ & $7.1 \pm 1.3$ & -15.5 \\
\hline
\end{tabular}

Values are means \pm standard error. ${ }^{* *}: \mathrm{p}<0.01$ when compared with control.

PBZ : Phenoxybenzamine.

d. Adrenaline 性 $\beta$ 遮断薬

ストレス非負荷時, propranolol $20 \mathrm{mg} / \mathrm{kg}$ は, 胃液分泌, PSB 量を減少したが, $\mathrm{pH}$ 上昇は明らかでなか った. DCI $40 \mathrm{mg} / \mathrm{kg}$ は, 胃液分泌の減少, $\mathrm{pH}$ 上昇とともに, PSB 量を明らかに減少した (Table 5).

ストレス負荷時, propranolol $20 \mathrm{mg} / \mathrm{kg}$ は, 胃液分泌減少, $\mathrm{pH}$ 上昇をきたしたが, PSB 量減少を阻止す る傾向であった。 DCI $40 \mathrm{mg} / \mathrm{kg}$ も, 胃液分泌の減少, $\mathrm{pH}$ 上昇をきたしたが, PSB 量減少にむしろ阻止的で あった (Table 5).

Table 5. Effect of $\beta$-adrenergic blocking agents on gastric secretion and output of PSB in stressed and non-stressed rats.

\begin{tabular}{|c|c|c|c|c|c|c|}
\hline \multirow{2}{*}{ Treatment } & \multirow{2}{*}{$\begin{array}{c}\text { Dose } \\
(\mathrm{mg} / \mathrm{kg})\end{array}$} & \multirow{2}{*}{$\begin{array}{l}\text { No. of } \\
\text { rats }\end{array}$} & \multirow{2}{*}{$\begin{array}{c}\text { Volume } \\
\mathrm{ml}\end{array}$} & \multirow{2}{*}{$\mathrm{pH}$} & \multicolumn{2}{|c|}{ PSB output } \\
\hline & & & & & $\mu \mathrm{g} / 100 \mathrm{~g}$ & $\%$ change \\
\hline \multicolumn{7}{|l|}{ Non-stressed } \\
\hline Control & & 9 & $5.6 \pm 0.8$ & $1.1 \pm 0.1$ & $21.5 \pm 4.4$ & \\
\hline Propranolol & 20 & 10 & $2.6 \pm 0.6 * *$ & $1.3 \pm 0.1$ & $15.2 \pm 2.8$ & -29.3 \\
\hline Control & & 12 & $5.0 \pm 0.4$ & $1.3 \pm 0.1$ & $25.7 \pm 4.3$ & \\
\hline $\mathrm{DCI}$ & 40 & 11 & $1.3 \pm 0.8^{* *}$ & $2.8 \pm 0.7 * *$ & $12.0 \pm 0.3^{*}$ & -53.3 \\
\hline \multicolumn{7}{|l|}{ Stressed } \\
\hline Control & & 10 & $1.0 \pm 0.3$ & $1.6 \pm 0.1$ & $9.8 \pm 1.9$ & \\
\hline Propranolol & 20 & 10 & $0.5 \pm 0.2$ & $2.3 \pm 0.1 * *$ & $10.6 \pm 2.1$ & 7.5 \\
\hline Control & & 10 & $0.8 \pm 0.3$ & $1.7 \pm 0.1$ & $7.2 \pm 1.8$ & \\
\hline $\mathrm{DCI}$ & 40 & 10 & $0.4 \pm 0.2$ & $2.8 \pm 0.6^{*}$ & $9.6 \pm 2.2$ & 33.3 \\
\hline
\end{tabular}

Values are means \pm standard error. ${ }^{* *}: \mathrm{p}<0.01 ; *^{*}: \mathrm{p}<0.05$ when compared to control.

DCI : Dichloroisoproterenol.

e . 平滑筋作用薬

ストレス非負荷時, papaverine $50 \mathrm{mg} / \mathrm{kg}$ は, 胃液分泌, pH 㧍よび PSB 量に有意の影響がなかった。 vasopressin $10 \mathrm{u} / \mathrm{kg}$ は, 胃液分泌を軽度に減少したが, pH には無影響であった。しかし, PSB 量を有意に 減少した (Table 6).

ストレス負荷時, papaverine $50 \mathrm{mg} / \mathrm{kg}$ は, 胃难分泌を減少し, PSB 量减少をやや增強した。 ただ, pH には影響がなかった。 vasopressin $10 \mathrm{u} / \mathrm{kg}$ は, 胃液分泌, $\mathrm{pH}$ に著明な影響はなく, PSB 量減少の增強子軽 度であった (Table 6). 
Table 6. Effect of musculotropic agents on gastric secretion and output of PSB in stressed and non-stressed rats.

\begin{tabular}{|c|c|c|c|c|c|c|}
\hline \multirow{2}{*}{ Treatment } & \multirow{2}{*}{$\begin{array}{c}\text { Dose } \\
(\mathrm{mg} / \mathrm{kg})\end{array}$} & \multirow{2}{*}{$\begin{array}{l}\text { No. of } \\
\text { rats }\end{array}$} & \multirow{2}{*}{$\begin{array}{l}\text { Volume } \\
\mathrm{ml}\end{array}$} & \multirow{2}{*}{$\mathrm{pH}$} & \multicolumn{2}{|c|}{ PSB output } \\
\hline & & & & & $\mu \mathrm{g} / 100 \mathrm{~g}$ & $\%$ change \\
\hline \multicolumn{7}{|l|}{ Non-stressed } \\
\hline Control & & 8 & $3.9 \pm 0.7$ & $1.7 \pm 0.5$ & $13.0 \pm 3.0$ & \\
\hline Papaverine & 50 & 8 & $3.8 \pm 0.3$ & $1.2 \pm 0.1$ & $13.3 \pm 3.6$ & 2.3 \\
\hline Control & & 8 & $\quad 3.7 \pm 0.6$ & $1.5 \pm 0.1$ & $28.0 \pm 5.4$ & \\
\hline Vasopressin & $10 \mathrm{u} / \mathrm{kg}$ & 7 & $2.7 \pm 0.5$ & $1.5 \pm 0.1$ & $11.2 \pm 1.9 * *$ & -60.7 \\
\hline Stressed & & & & & & \\
\hline Control & & 7 & $1.3 \pm 0.2$ & $1.4 \pm 0.1$ & $6.2 \pm 2.5$ & \\
\hline Papaverine & 50 & 8 & $0.8 \pm 0.2$ & $1.5 \pm 0.1$ & $4.5 \pm 1.0$ & -27.4 \\
\hline Control & & 8 & $0.9 \pm 0.2$ & $1.6 \pm 0.1$ & $9.8 \pm 2.7$ & \\
\hline Vasopressin & $10 \mathrm{u} / \mathrm{kg}$ & 7 & $0.8 \pm 0.2$ & $1.8 \pm 0.3$ & $7.7 \pm 1.0$ & -21.4 \\
\hline
\end{tabular}

Values are means \pm standard error. $* *: \mathrm{p}<0.01$ when compared to control.

f . 中权抑制薬

ストレス非負荷時, chlorpromazine $5 \mathrm{mg} / \mathrm{kg}$ は, 胃液分泌を阻止し， $\mathrm{pH}$ を上昇するとともに, PSB 量 を減少した. pentobarbital $20 \mathrm{mg} / \mathrm{kg}$ も同様の傾向を示したが, いずれも軽度であった (Table 7).

ストレス負荷時には, chlorpromazine $5 \mathrm{mg} / \mathrm{kg}$ は，胃液分泌減少， pH 上昇とともに，PSB 量減少をむ しろ阻止した。一方, pentobarbital $20 \mathrm{mg} / \mathrm{kg}$ は, 胃液分泌と $\mathrm{pH}$ に対し，ストレス負荷自体以上の影響を与 えなかったが, PSB 量減少に対しては軽度の増強を示した (Table 7).

Table 7. Effect of central nervous system depressants on gastric secretion and output of PSB in stressed and non-stressed rats.

\begin{tabular}{|c|c|c|c|c|c|c|}
\hline \multirow{2}{*}{ Treatment } & \multirow{2}{*}{$\begin{array}{c}\text { Dose } \\
(\mathrm{mg} / \mathrm{kg})\end{array}$} & \multirow{2}{*}{$\begin{array}{c}\text { No. of } \\
\text { rats }\end{array}$} & \multirow{2}{*}{$\begin{array}{l}\text { Volume } \\
\text { ml }\end{array}$} & \multirow{2}{*}{$\mathrm{pH}$} & \multicolumn{2}{|c|}{ PSB output } \\
\hline & & & & & $\mu \mathrm{g} / 100 \mathrm{~g}$ & $\%$ change \\
\hline Non-stressed & & & & & & : \\
\hline Control & & 8 & $5.5 \pm 0.4$ & $1.0 \pm 0.1$ & $34.6 \pm 8.9$ & \\
\hline $\mathrm{CPZ}$ & 5 & 8 & $0 * *$ & $3.8 \pm 0.8 * *$ & $20.8 \pm 4.8$ & -39.1 \\
\hline Pent & 20 & 8 & $1.7 \pm 0.4^{* *}$ & $1.8 \pm 0.3^{* *}$ & $28.8 \pm 8.8$ & -16.8 \\
\hline \multicolumn{7}{|l|}{ Stressed } \\
\hline Control & & 8 & $0.9 \pm 0.2$ & $1.5 \pm 0.1$ & $13.5 \pm 1.3$ & \\
\hline $\mathrm{CPZ}$ & 5 & 8 & $0.2 \pm 0.1 * *$ & $2.5 \pm 0.5^{*}$ & $22.1 \pm 5.8$ & 38.9 \\
\hline Pent & 20 & 8 & $0.9 \pm 0.2$ & $1.4 \pm 0.1$ & $10.5 \pm 4.4$ & -22.3 \\
\hline
\end{tabular}

Values are means \pm standard error. **: $\mathrm{p}<0.01 ; *: \mathrm{p}<0.05$ when compared to control.

$\mathrm{CPZ}$ : Chlorpromazine. Pent: Pentobarbital-Na.

\section{考察}

ストレス潰瘍発生の重要な要因として，微小循環における血行障害の関与を示した報告は数多い6 12)。さき に私たちは1,2), ストレス負荷時に胃液中への PSB 漏出量が減少すること, reserpine その他数種薬物の潰瘍抑 制と PSB 量減少間に相関のあること, および, PSB 量は胃壁血流量の指標となり得ることを示唆した。

本実験では, 自律神経薬ほか二, 三薬物のストレス負荷時潰瘍形成と胃液分泌および上記 PSB 量測定によ る胃壁血流量への影響をしらべた。

従来, 副交感神経遮断薬および節遮断薬の潰瘍抑制効果には, 胃液分泌抑制作用の関与することは多くの研 
究者の認めるところである。実際, atropine, scopolamine, hexamethonium は胃液分泌抑制と $\mathrm{pH}$ 上昇作用 を示した。

Adrenaline 性遮断薬については， dibenamine が，胃液分泌を減少し，pH の上昇傾向を示したにかかわ らず抗潰瘍作用を示さなかったのに詨し，PBZ は胃液分泌，pH に影響しなかったが，抗潰瘍作用を示した． $\beta$ 遮断薬については, propranolol, DCI ともに胃液分泌の減少の傾向を示し，また， pH の上昇がみられ，両 者ともに抗潰瘍作用を示した.

平滑筋作用薬 papaverine, vasopressin は，胃液分泌および $\mathrm{pH}$ に著明な影響がなく，抗潰瘍作用もなか った。

中枢抑制薬 chlorpromazine は，胃液分泌抑制と $\mathrm{pH}$ 上昇とともに抗潰瘍作用が著るしかったのに対し， pentobarbital はいずれも著明でなかった，すなわち，PBZをのぞき，潰瘍抑制作用を示す薬物は，胃液分泌減 少と $\mathrm{pH}$ 上昇作用を呈することから，ストレス潰瘍抑制には胃液分泌の抑制が重要な因子と考えられる．ただ， Brodie たち $\left.{ }^{13}\right)$ は, atropine や chlorpromazine が，胃液分泌抑制量においてストレス潰瘍を抑制しないことよ りこれらのストレス潰瘍抑制効果には胃酸分泌以外の因子の関与することを示唆した：本実験において atropine は，潰瘍抑制用量において，胃酸分泌を阻止し， pH を上昇するとともに，ストレスによる PSB 量減少 を少くとも増強することはなかった, propranolol, DCI, chlorpromazine は, PSB 量減少に対し，むしろ阻止 的であった。これらの薬物では，ストレスによる胃粘膜血流減少の阻止ないし抑制が抗潰瘍作用の一因となるの であろう。

Okabe たち ${ }^{144}$ は，ストレス潰瘍に対する $\alpha$ および $\beta$ 遮断薬の影響を検討し， phentolamine， tolazoline が胃酸分泌を有意に抑制するにかかわらず, 潰瘍を悪化することを認め, 潰瘍発生に胃酸以外の因子の関与の重 要なことを示唆した. dibenamine が胃酸分泌を抑制し, atropine と同様にストレスによるPSB 量减少を增強 しなかったにかかわらず，抗潰瘍作用の認められなかった点は，今後の検討を必要としょう.

謝辞：稿を終るに臨み，御校閲を賜った京都大学医学部薬理学教室藤原元始教授に深く感謝いたします。また， 本研究に発表の機会をあた只られた大正製薬上原昭二副社長, 井川俊一常務取締役および田中一郎研究部長に謝 意を表わします。なお，本実験に協力された新井雄一氏に感謝いたします。

\section{文献}

1）中根貞雄，酒井 健：日薬理誌（投稿中）

2) 中根貞雄, 新井雄一, 酒井 健 : 日薬理誌 68, $163 \mathrm{p}$ (1972)

3) TAKagi, K. and OKabe, S. : Japan. J. Pharmacol. 18, 9 (1969)

4) BRodie, D. A. and Hanson, H. M. : Gastroenterology 38, 353 (1960)

5) Takagi, K. and Kawashima, K. : Japan. J. Pharmacol. 19, 431 (1969)

6）西崎弘之，伊藤隆太：日薬理誌 65，56§（1969）

7）松尾 裕, 関 敦子, 安孫子 惊, 小西建吉, 北村達也：診療 20,172（1967）

8）宾戸輝男：日消誌 67, 190 (1970)

9) Leonald, A. S., Long, D., French, L. A., Peter, E. T. and Wangensteen, O. H. : Surgery 56, 109 (1964)

10) Guth, P.H. and Kozbur, X.: Am. J. Dig. Die, 13, 530 (1968)

11) GuTH, P. H. and HALl, P. : Gastroenterology 50, 502 (1966)

12) Sethbhakdi, S., Pfeiffer, C. J. and Roth, J. L. A. : Am. J. Dig. Die. 15, 261 (1970)

13) Brodie, D. A., Lotti, V. J. and Bauer, B. G. : Am. J. Dig. Die. 15, 111 (1970)

14) OKabe, S., Saziki, R. and Takagi, K. : Japan. J. Pharmacol. 20, 10 (1970).

Abstract-Sadao NAKANE and Takeshi SAKAI (Division of Pharmacology, Taisho Pharmaceutical Co. Ltd., Tokyo). Effect of drugs on stress ulcer and secretion in stomach. Folia pharmacol. japon. 70, $1 \sim 7$ (1974).

The present experiments were carried out to determine the effect of drugs on the production of stress ulcer and output of Pontamine Sky Blue 6BX (PSB) in gastric juice and gastric secretion. The following results were obtained. Drugs inhibiting ulceration (except phenoxybenzamine) decreased gastric 
secretion and increased the $\mathrm{pH}$ value of gastric juice in rats. It is therefore suggested that the reduction of gastric juice may play an important role in prevention of stress ulcer. Propranolol, DCI and chlorpromazine prevented the decrease in output of PSB, as observed under stress. These results indicate, that prevention of stress-induced decrease in blood flow to the stomach wall may contribute to the inhibition of stress ulcer. 